\title{
Impact of multimodal treatment on patient outcomes and prognosis in colorectal peritoneal metastases
}

Citation for published version (APA):

Bakkers, C. (2021). Impact of multimodal treatment on patient outcomes and prognosis in colorectal peritoneal metastases. [Doctoral Thesis, Maastricht University]. Maastricht University. https://doi.org/10.26481/dis.20211203cb

Document status and date:

Published: 01/01/2021

DOI:

$10.26481 /$ dis.20211203cb

Document Version:

Publisher's PDF, also known as Version of record

\section{Please check the document version of this publication:}

- A submitted manuscript is the version of the article upon submission and before peer-review. There can be important differences between the submitted version and the official published version of record. People interested in the research are advised to contact the author for the final version of the publication, or visit the DOI to the publisher's website.

- The final author version and the galley proof are versions of the publication after peer review.

- The final published version features the final layout of the paper including the volume, issue and page numbers.

Link to publication

\footnotetext{
General rights rights.

- You may freely distribute the URL identifying the publication in the public portal. please follow below link for the End User Agreement:

www.umlib.nl/taverne-license

Take down policy

If you believe that this document breaches copyright please contact us at:

repository@maastrichtuniversity.nl

providing details and we will investigate your claim.
}

Copyright and moral rights for the publications made accessible in the public portal are retained by the authors and/or other copyright owners and it is a condition of accessing publications that users recognise and abide by the legal requirements associated with these

- Users may download and print one copy of any publication from the public portal for the purpose of private study or research.

- You may not further distribute the material or use it for any profit-making activity or commercial gain

If the publication is distributed under the terms of Article $25 \mathrm{fa}$ of the Dutch Copyright Act, indicated by the "Taverne" license above, 


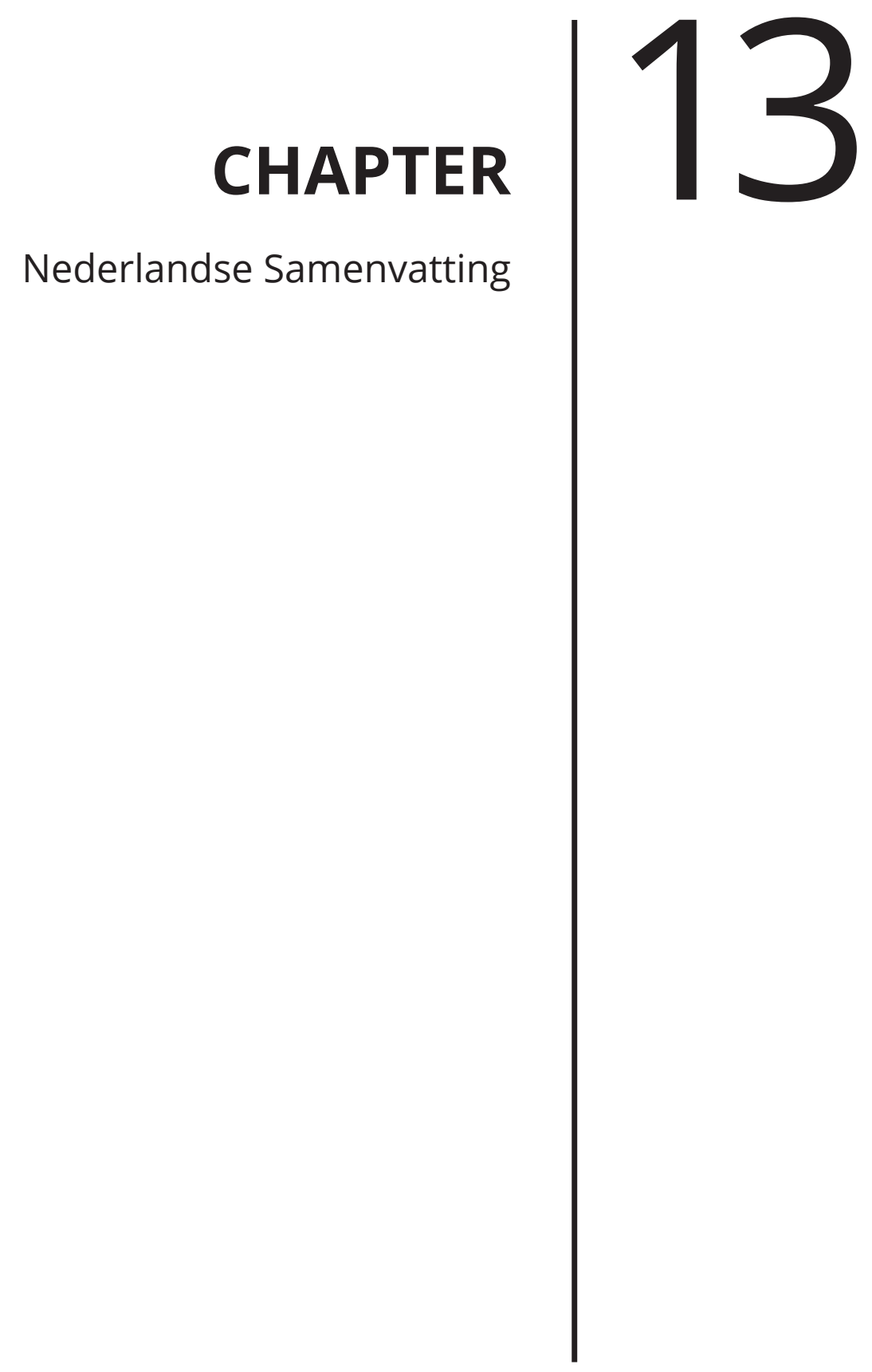




\section{Het colorectaal carcinoom}

Dikke darmkanker, oftewel het colorectaal carcinoom, wordt elk jaar in meer dan een miljoen mensen wereldwijd vastgesteld. Daarmee is het de derde meest voorkomende kankersoort. ${ }^{1}$ In Nederland worden er elk jaar 14.000 nieuwe patiënten gediagnosticeerd met een colorectaal carcinoom en overlijden er jaarlijks zo'n 5000 patiënten aan. ${ }^{2}$ Zowel ten tijde van diagnose, als later tijdens de follow-up kunnen uitzaaiingen (metastasen) ontstaan. De meest voorkomende plekken waar deze metastasen ontstaan, zijn de lever, het buikvlies (peritoneum) en de longen. ${ }^{3,4}$ Wanneer er sprake is van gemetastaseerde ziekte, verslechtert de prognose significant: deze patiëntengroep kent een vijfjaarsoverleving van $11 \%$, waar de patiëntengroep met niet-gemetastaseerde ziekte een vijfjaarsoverleving van $71 \%$ heeft. $^{2}$ Bij patiënten met peritoneale metastasen is deze prognose daarnaast ook nog slechter dan bij patiënten met levermetastasen. ${ }^{3,5}$ In de afgelopen decennia is er uitgebreid onderzoek verricht naar de optimalisatie van de behandeling voor patiënten met colorectale levermetastasen. ${ }^{6,7}$ Echter, binnen de peritoneale metastasen is er veel minder bekend over de optimale behandeling, 8,9 ondanks het aanzienlijk aantal patiënten dat hiermee te maken krijgt en de slechte prognose.

\section{Peritoneale metastasen en hun behandeling}

Peritoneale metastasen kunnen afhankelijk van hun aantal, grootte en locatie voor ernstige symptomen zorgen. Echter, deze symptomen komen niet bij alle patiënten voor en wanneer ze voorkomen, is er vaak al sprake van gevorderde ziekte. $^{10}$ Ook doordat de huidige beeldvormende technieken slechts in beperkte mate deze afwijkingen kunnen detecteren, ${ }^{11}$ is de diagnose van deze peritoneale metastasen lastig. Als gevolg daarvan presenteert de meerderheid van de patiënten zich met al vergevorderde ziekte ten tijde van diagnose. ${ }^{12}$ Deze patiënten, evenals patiënten welke tevens metastasen op andere locaties hebben (levermetastasen of longmetastasen), komen alleen nog in aanmerking voor een palliatief behandeltraject.

Dit proefschrift richt zich voornamelijk op de patiëntengroep met beperkte intraperitoneale ziekte. Deze patiënten komen mogelijk in aanmerking voor cytoreductieve chirurgie met intraperitoneale, verwarmde chemotherapie (cytoreductive surgery and hyperthermic, intraperitoneal chemotherapy; CRS- 
HIPEC), hetgeen de voorkeursbehandeling is voor deze patiënten in Nederland en vele andere landen.9,13 Tijdens deze operatieve ingreep worden alle zichtbare tumordeposities door de chirurg verwijderd (CRS), waarna er verwarmde chemotherapie gecirculeerd wordt door de buikholte (HIPEC). Deze behandeling wordt tegenwoordig in ongeveer 430 gespecialiseerde centra wereldwijd toegepast, en resulteert in een vijfjaarsoverleving van ongeveer 30\%. Helaas keert bij de meeste patiënten de ziekte weer terug. Bij 35-41\% van de patiënten gebeurt dit al in het eerste jaar na CRS-HIPEC. ${ }^{14,15}$ Om de overleving te verbeteren, pleiten sommige clinici ervoor dat perioperatieve systemische chemotherapie (chemotherapie voorafgaand aan de operatie en na de operatie) moet worden toegevoegd aan de behandeling. Deze chemotherapie kan namelijk zorgen voor tumor downstaging voorafgaand aan de operatie, uitwassen van micrometastasen in de bloedbaan, en postoperatief uitroeien van achtergebleven kankercellen in de buikholte. Echter, andere experts opteren juist dat het geven van systemische chemotherapie rondom een ingrijpende operatie als CRS-HIPEC voor ernstige complicaties kan zorgen, met als gevolg verlies van kwaliteit van leven voor deze patiënten. Bovendien is nog nooit bewezen dat systemische chemotherapie werkzaam is voor deze vorm van kanker. In 2017 is er een systematic review gepubliceerd welke op basis van alle beschikbare literatuur concludeerde dat er geen eenduidig antwoord is op de vraag of systemische chemotherapie van meerwaarde is voor deze patiëntengroep. ${ }^{8}$

\section{Deel 1: een multimodale behandeling voor colorectale peritoneale metastasen}

\section{CAIRO6}

Om bovenstaande vraag te kunnen beantwoorden, is de CAIRO6 studie opgezet. In deze studie worden patiënten met colorectale peritoneale metastasen gerandomiseerd tussen CRS-HIPEC zónder perioperatieve systemische chemotherapie en CRS-HIPEC mét perioperatieve systemische chemotherapie. In hoofdstuk $\mathbf{2}$ staat in een protocol-samenvatting beschreven hoe deze studie in Nederland wordt uitgevoerd, met hierin details omtrent patiënten werving, randomisatie, chirurgische behandeling, systemische behandeling en follow-up. De CAIRO6 studie is opgesplitst in twee delen: de fase II studie en de fase III studie. De fase II studie, gericht op de veiligheid en haalbaarheid van de toepassing 
van systemische chemotherapie in deze setting betrof de eerste 80 patiënten. Voorafgaand aan de studie werden bepaalde voorwaarden (stop-criteria) opgesteld in overleg met een onafhankelijke beoordelingscommissie. Als niet aan deze stop-criteria werd voldaan, dan zou de onafhankelijke beoordelingscommissie voortzetting van de fase III studie goedkeuren. De primaire uitkomstmaat van de fase III studie is driejaarsoverleving, waarin de hypothese is gesteld dat de experimentele groep (CRS-HIPEC mét perioperatieve systemische chemotherapie) 15\% meer overleving zou laten zien dan de controlegroep (CRS-HIPEC zónder perioperatieve systemische chemotherapie; $65 \%$ vs. 50\%). Belangrijke secundaire uitkomstmaten voor de fase III studie zijn chirurgische karakteristieken, ernstige postoperatieve morbiditeit, progressievrije overleving, ziektevrije overleving, kwaliteit van leven, kosten, ernstige toxiciteit gerelateerd aan systemische chemotherapie, en objectiveerbare radiologische en pathologische respons op neoadjuvante systemische chemotherapie. Deze studie is de eerste en momenteel enige gerandomiseerde studie wereldwijd welke deze systemische chemotherapie onderzoekt als aanvulling op CRS-HIPEC in deze patiëntengroep.

In januari 2019 is de $80^{\mathrm{e}}$ patiënt geïncludeerd in de CAIRO6 fase II studie. De resultaten van deze fase II studie zijn beschreven in hoofdstuk 3 . Alle 80 patiënten zijn geïncludeerd binnen 1 jaar na opening van het laatste studiecentrum, wat erop wijst dat de studie haalbaar is in uitvoering (vooraf gestelde voorwaarde 1). Het percentage complete CRS-HIPEC procedures en het percentage ernstige postoperatieve complicaties (Clavien-Dindo $\geq 3$ ) was in beide groepen gelijk, er zijn geen patiënten overleden, en alle patiënten in de experimentele arm zijn gepland voor CRS-HIPEC na hun neoadjuvante traject. Hieruit blijkt dat het geven van systemische chemotherapie in deze setting veilig is (vooraf gestelde voorwaarde 2). Het percentage complete CRS-HIPEC procedures binnen de CAIRO6 fase II studie (89\%) was aanzienlijk hoger in vergelijking met twee eerder uitgevoerde enkel-armige studies welke perioperatieve systemische therapie voor geïsoleerde colorectale peritoneale metastasen onderzochten (56-57\%). ${ }^{16,17}$ Waarschijnlijk komt dit doordat binnen deze studies, in tegenstelling tot de CAIRO6 studie, beoordeling van resectabiliteit door middel van laparoscopie of laparotomie niet noodzakelijk was alvorens patiënten geïncludeerd mochten worden. Dit, tezamen met de verschillen in de (duur van) chemotherapeutica tussen deze studies, zal de vergelijking van uiteindelijke overlevingsresultaten tussen deze studies 
bemoeilijken. Het percentage graad 3-4 systemische therapie geassocieerde toxiciteit in de CAIRO6 fase II trial (CTCAE $\square 3$ ) was lager (35\%) dan in eerder gepubliceerde trials welke eerstelijns palliatieve systemische chemotherapie met bevacizumab onderzochten in patiënten met gemetastaseerd colorectaal carcinoom, ${ }^{18}$ wat verklaard zou kunnen worden door verschillen in patiëntselectie, uitgebreidheid van ziekte, en (duur van) systemische behandeling. Behalve dat deze aangetoonde veiligheid in de fase II studie ertoe heeft geleid dat de fase III studie voortgezet mag worden, kunnen deze resultaten bijdragen aan beter inzicht in de veiligheid en haalbaarheid van perioperatieve systemische therapie in de klinische praktijk. Tevens kunnen deze resultaten bijdragen aan de inclusie van patiënten in de CAIRO6 fase III studie.

\section{Patient-reported outcomes}

In hoofdstuk 4 van dit proefschrift is beschreven hoe de kwaliteit van leven (uitgedrukt in patient-reported outcomes; PROs) van patiënten in de controle en de experimentele groep was tijdens en na afronding van hun behandeling. De kwaliteit van leven werd voor aanvang van behandeling, drie maanden na CRSHIPEC en zes maanden na CRS-HIPEC gemeten middels gestandaardiseerde vragenlijsten. Bij patiënten in de experimentele arm werd de kwaliteit van leven nog eenmaal extra gemeten, na de afronding van het neoadjuvante behandelingstraject met systemische therapie, voor CRS-HIPEC. De vergelijking van deze twee behandelingsstrategieën in deze setting met focus op PROs was nog nooit eerder uitgevoerd. Met daarbij dus ook een afwezig referentiekader in de bestaande literatuur, werd er pragmatisch gekozen voor een vijftal vooraf gedefinieerde uitkomstmaten: visual analogue scale, global health status, C30 summary score, fysiek functioneren, en vermoeidheid. Geen enkele van deze uitkomstmaten was significant verschillend tussen de groepen op geen enkele van de meetmomenten. Daarnaast herstelden de waarden van alle uitkomstmaten naar baseline waarden op drie of zes maanden na CRS-HIPEC. Deze resultaten tonen aan dat perioperatieve systemische therapie geen additionele negatieve invloed op PROs heeft ten opzichte van CRS-HIPEC alleen, en dat alle postoperatieve dalingen tijdelijk waren, omdat alle waarden terug herstelden naar baseline waarden binnen zes maanden na CRS-HIPEC.

Als gevolg van deze resultaten omtrent veiligheid, haalbaarheid en PROs heeft de 
onafhankelijke beoordelingscommissie akkoord gegeven op het continueren van de CAIRO6 fase III studie. Uiteindelijk zullen 358 patiënten geïncludeerd worden in de gehele CAIRO6 studie waarbij bovengenoemde primaire en secundaire eindpunten getoetst zullen worden.

In hoofdstuk $\mathbf{5}$ wordt de kwaliteit van leven van de hierboven beschreven patiënten in de CAIRO6 fase II studie vergeleken met de kwaliteit van leven in patiënten welke conventionele chirurgie ondergaan voor een primair colorectaal carcinoom. Deze laatste groep betreft meer dan een miljoen patiënten per jaar wereldwijd. Derhalve is er binnen deze groep veel ervaring en kennis opgedaan met betrekking tot kwaliteit van leven en de invloed van behandeling daarop. Doordat tijdens CRS-HIPEC gestreefd wordt naar een macroscopisch radicale resectie, betreft deze ingreep doorgaans een veel uitgebreidere resectie dan een conventionele darmresectie. Als gevolg gaat deze uitgebreidere ingreep gepaard met een hoger morbiditeits- en mortaliteitsrisico, wat een grote impact op de ziektelast van de patiënt heeft, en daarmee de kwaliteit van leven beïnvloedt.

In de analyses waren ditmaal negen vooraf gedefinieerde uitkomstmaten (vermoeidheid, diarree, C30 summary score, global health status, fysiek -, rol -, emotioneel -, cognitief -, en sociaal-functioneren) opgenomen en werd vergeleken tussen de groepen op drie meetmomenten: baseline (voor start behandeling), in de vroege postoperatieve periode, en een jaar postoperatief. In de analyses werd gecorrigeerd voor eventuele gegeven systemische chemotherapie in beide groepen. Uit de resultaten bleek dat CRS-HIPEC geen grotere impact had op PROs dan conventionele chirurgie voor het primair colorectaal carcinoom. Er werd in de vroege postoperatieve periode een verslechtering van vermoeidheid, C30 summary score, fysiek-, en rol-functioneren gezien in beide groepen en een verslechtering van cognitief- en sociaal-functioneren in de conventionele chirurgie groep. Een jaar na de operatie waren alle waarden weer hersteld naar baseline waarden. Additionele systemische chemotherapie bleek geen significant effect op de scores te hebben. Hieruit kan geconcludeerd worden dat ondanks een uitgebreidere operatie met een groter morbiditeitsrisico, CRS-HIPEC in patiënten met colorectale peritoneale metastasen geen grotere impact had op postoperatieve PROs vergeleken met conventionele darmresecties in patiënten met een primair colorectaal carcinoom, en dat additionele systemische chemotherapie hier geen significant effect op had. Deze studie biedt nieuwe inzichten in de impact van 
behandeling op kwaliteit van leven in patiënten welke CRS-HIPEC ondergaan in verband met colorectale peritoneale metastasen. Dit is informatief voor clinici en patiënten wereldwijd en kan bijdragen aan een betere patiëntenvoorlichting voor deze patiëntengroep.

\section{Deel 2: population-based studies in patiënten met colorectale peritoneale metastasen}

De behandeling van colorectale peritoneale metastasen is niet in alle landen hetzelfde, en ook in landen zijn er door de jaren heen aanpassingen gemaakt in richtlijnen, omdat de opvatting over wat de beste behandelingsstrategie voor deze patiënten is aan veranderingen onderhevig is. Voor 2014 stond er in de Nederlandse richtlijn voor het behandelen van peritoneale metastasen niets opgenomen over het geven van adjuvante systemische therapie na CRS-HIPEC. In 2014 is deze richtlijn vernieuwd, waarna in de richtlijn werd opgenomen dat adjuvante systemische therapie overwogen kon worden, ${ }^{19}$ waarmee het uiteindelijke besluit nog steeds werd gedreven door de voorkeur van arts en patiënt. In de praktijk werd adjuvante systemische therapie in Nederland veel gegeven. In 2017 is er een systematic review gepubliceerd welke geen correlatie tussen adjuvante systemische therapie en een betere prognose liet zien. ${ }^{8}$ Sindsdien wordt adjuvante systemische therapie in Nederland niet meer gegeven. Echter, het ontbrak aan vergelijkende studies van deze twee behandelingsstrategieën op populatie-niveau. Eerdere studies omtrent deze vraag hadden patiënten met incomplete cytoreducties, ${ }^{20-27}$ extraperitoneale metatasen, ${ }^{20-22,25-31}$ appendix tumoren, ${ }^{20,26,27}$ of neoadjuvante systemische therapie voor CRS-HIPEC 20-22,24-30 geïncludeerd. Resultaten van dergelijke studies zijn daarom niet interpretabel op de Nederlandse patiëntenpopulatie welke upfront (zonder systemische voorbehandeling) CRS-HIPEC ondergaat. Hoofdstuk 6 van dit proefschrift bevat deze vergelijking binnen een landelijke studie waarin alle patiënten upfront CRS-HIPEC hebben ondergaan voor synchrone colorectale peritoneale metastasen. Algehele overleving was significant beter in patiënten welke adjuvante systemische therapie ondergingen (mediane overleving 39 maanden) vergeleken met patiënten welke geen adjuvante systemische therapie ondergingen (mediane overleving 25 maanden). Alhoewel er in deze studie rekening is gehouden met immortal time bias, hetgeen in eerder uitgevoerde bovengenoemde studies niet gedaan was, kunnen de resultaten van deze studie 
nog steeds onderhevig zijn aan bias. Het feit dat het verschil in overleving tussen de groepen al op 3 maanden na operatie zichtbaar wordt, kan duiden op een residuale selectie bias op basis van factoren die niet in de studie mee konden zijn genomen (bijvoorbeeld postoperatieve morbiditeit), ondanks de toepassing van propensity score matching bij analyses. Als gevolg hiervan kan er sprake zijn van een overschatting van de associatie tussen adjuvante systemische therapie en verbeterde overleving. Ondanks dat resultaten van de CAIRO6 fase III studie binnen enkele jaren beschikbaar zullen zijn, kunnen de resultaten van deze studie reeds dienen als ondersteuning voor klinische besluitvorming in deze patiëntengroep. Tevens, indien de CAIRO6 studie geen superioriteit voor neoadjuvante systemische therapie aantoont, zal upfront CRS-HIPEC de standaardbehandeling blijven en zal het al dan niet geven van adjuvante systemische therapie een internationaal discussiepunt blijven. Wanneer neoadjuvante systemische therapie wel onderdeel van de standaardbehandeling wordt, zullen er altijd patiënten blijven die upfront CRS-HIPEC ondergaan (bijvoorbeeld in een spoedoperatie). In beide situaties blijven de data van deze studie waardevol voor de beslissing omtrent adjuvante systemische therapie na CRS-HIPEC.

In hoofdstuk 7 wordt de vergelijking van de effectiviteit van de twee meest gebruikte chemotherapeutica tijdens HIPEC weergegeven: oxaliplatin en mitomycine C. Binnen deze studie werden patiënten welke CRS-HIPEC ondergingen voor colorectale peritoneale metastasen tussen 2014 en 2017 geïncludeerd. Alle patiënten worden in Nederland volgens hetzelfde HIPEC-protocol behandeld, waardoor de selectie van patiënten geschikt voor deze operatie, pre- en postoperatieve zorg, en chirurgische karakteristieken bij deze patiënten allemaal gelijk zijn. Het enige variabele binnen deze behandeling is het spoelmiddel wat gebruikt wordt tijdens HIPEC, welk nu op basis van de voorkeur van ziekenhuis of chirurg gekozen wordt. De mediane algehele overleving was 47 maanden in patiënten welke oxaliplatin kregen en 31 maanden in patiënten welke mitomycine $\mathrm{C}$ kregen. Ondanks dat dit verschil evident lijkt, was dit niet significant verschillend tussen de twee groepen. Op basis van deze studie kan men dus rechtvaardigen om beide middelen te gebruiken tijdens HIPEC. Echter, terwijl de studies uit deze thesis werden uitgevoerd, speelde er een wereldwijde discussie tussen experts en clinici omtrent de behandeling van colorectale peritoneale metastasen. De aanleiding hiervoor was de presentatie van preliminaire resultaten van de Franse PRODIGE-7 studiegroep op het jaarlijkse ASCO congres in 2018. ${ }^{32}$ Hun studie 
toonde geen superioriteit van CRS-HIPEC over CRS alleen: de algehele overleving was niet significant verschillend tussen patiënten welke enkel cytoreductieve chirurgie (CRS) ondergingen en patiënten welke cytoreductieve chirurgie, gevolgd door HIPEC (CRS-HIPEC) ondergingen. Binnen deze studie werden alle HIPEC procedures uitgevoerd met oxaliplatin. De gerapporteerde overleving binnen deze studie was uitzonderlijk hoog (mediane overleving 41 maanden) in vergelijking met eerder gepubliceerde overlevingscijfers in deze patiëntencategorie welke CRSHIPEC ondergingen (mediane overleving maximaal 36 maanden). ${ }^{33,34}$ Alhoewel dit veelbelovend lijkt, dient men rekening te houden met een zekere selectie bias in deze studie, daar alleen patiënten geïncludeerd werden welk minstens 6 cycli of systemische therapie ondergingen en welke allen complete CRS-HIPEC ondergingen. Dit fenomeen roept vragen op omtrent de externe validiteit van deze trial. Desalniettemin, waar de uiteindelijke resultaten nog steeds op zich laten wachten, zou er geconcludeerd kunnen worden dat HIPEC met oxaliplatin toch ineffectief blijkt, in tegenstelling tot de bevindingen in de vergelijkende studie welke in dit proefschrift is opgenomen.

Eerder gepubliceerde landelijke studies over de incidentie van en risicofactoren voor colorectale peritoneale metastasen baseerden zich op cohorten van patiënten welke waren gediagnosticeerd met colorectale peritoneale metastasen tussen 1995 en 2008. ${ }^{3-5,35,36}$ Gezien het feit dat de (systemische) behandelingen, beeldvormende technieken en kennis binnen dit ziektebeeld sterk zijn verbeterd in de afgelopen jaren, werd een update-studie uitgevoerd. In hoofdstuk 8 zijn de resultaten van deze landelijke studie opgenomen. In deze studie worden de incidentie van synchrone (5.7\%) en metachrone $5.5 \%$ [3-jaars cumulatieve incidentie]) peritoneale metastasen beschreven, welke de hoogst beschreven incidenties zijn in de huidige beschikbare literatuur. Behalve de toegenomen incidentie werd er ook een sterke correlatie tussen de aanwezigheid van synchrone systemische metastasen en de ontwikkeling van zowel synchrone als metachrone peritoneale metastasen gezien. Waar door verbeteringen in behandelingen tegenwoordig steeds meer patiënten in opzet curatief behandeld kunnen worden, is deze bevinding omtrent systemische metastasen erg waardevol voor de klinische praktijk. Zo kunnen de bevindingen van deze studie fungeren als de basis voor toekomstige klinische studies waarin nieuwe strategieën omtrent risico-reductie of vroege detectie van metachrone colorectale peritoneale metastasen worden onderzocht. 
In hoofdstuk 9 wordt beschreven hoe patiënten met synchrone of metachrone peritoneale metastasen in Nederland worden behandeld en wat de prognose van deze patiënten is. Ongecorrigeerde mediane overleving bleek beter in patiënten met metachrone peritoneale metastasen dan in patiënten met synchrone peritoneale metastasen: 12 maanden vs. 8 maanden, respectievelijk. Na correctie voor alle variabelen welke in univariabele analyses geassocieerd waren met overleving, bleek er geen verschil meer te bestaan in algehele overleving tussen de twee groepen. Echter, significant meer patiënten met metachrone peritoneale metastasen ondergingen CRS-HIPEC (16\%) in vergelijking met patiënten met synchrone peritoneale metastasen (8\%). Dit zou verklaard kunnen worden door het fenomeen dat patiënten na primaire colorectale chirurgie gestandaardiseerde follow-up ondergaan, wat geresulteerd kan hebben in de vroege diagnose van minder vergevorderde metastasen. Aan de andere kant kunnen patiënten met synchrone peritoneale metastasen lang onopgemerkt blijven aangezien veel patiënten asymptomatisch blijven. ${ }^{37}$ Tevens worden synchrone peritoneale metastasen frequent ontdekt (in een spoedsetting) in ziekenhuizen welke niet gespecialiseerd zijn in CRS-HIPEC. Het is bekend dat het centrum waar de peritoneale metastasen voor het eerst gezien zijn invloed heeft op de uiteindelijke kans om CRS-HIPEC te ondergaan. ${ }^{38}$ Helaas was er binnen onze studie geen data beschikbaar met betrekking tot de uitgebreidheid van intraperitoneale ziekte (peritoneal cancer index; $\mathrm{PCI}$ ), hetgeen de belangrijkste factor is bij het bepalen of een patiënt in aanmerking komt voor CRS-HIPEC, en welke een sterke associatie met prognose kent. Binnen alle patiënten welke CRS-HIPEC ondergingen bleken zowel ziektevrije overleving als algehele overleving niet significant te verschillen tussen patiënten met synchrone en metachrone peritoneale metastasen. Deze bevindingen zijn niet conform resultaten uit eerdere (niet landelijke) studies welke deze vraag onderzochten: een studie vond betere ziektevrije overleving in patiënten met synchrone peritoneale metastasen zonder een verschil in algehele overleving, ${ }^{39}$ terwijl een andere studie juist betere algehele overleving vond in patiënten met metachrone peritoneale metastasen zonder verschillen in ziektevrije overleving. ${ }^{40}$ Bevindingen van onze studie suggereren dat de timing van het ontwikkelen van peritoneale metastasen niet in acht hoeft worden genomen bij het bepalen van de beste behandelstrategie voor patiënten noch dat dit als stratificatiefactor in klinische trials meegenomen hoeft te worden. 
Er bestaat een voortdurende discussie omtrent de ontstaanswijze van ovariële metastasen vanuit het colorectaal carcinoom. Sommige experts zijn van mening dat ovariële metastasen resulteren uit lymfatische verspreiding van tumorcellen, waar anderen vinden dat deze ovariële metastasen ontstaan als gevolg van hematogene verspreiding. ${ }^{41-43}$ Er zijn steeds meer experts die ovariële metastasen beschouwen als het resultaat van peritoneale verspreiding van tumorcellen, en daarmee wordt gepleit om deze patiënten te behandelen middels CRS-HIPEC. Hoofdstuk 10 van dit proefschrift omvat een landelijke studie omtrent de incidentie, behandelingen, risicofactoren en overleving van patiënten met ovariële metastasen van colorectale origine. Een incidentie van $4 \%$ in alle vrouwelijke patiënten met gemetastaseerd colorectaal carcinoom werd gevonden. Eerdere studies (weliswaar uitgevoerd met behulp van ziekenhuis cohorten in plaats van landelijke cohorten) toonden een incidentie tussen de 3\% en 14\%.44,45 Vrouwen onder de vijftig jaar liepen meer risico op het ontwikkelen van ovariële metastasen vergeleken met vrouwen boven de vijftig jaar. Dit ondersteunt de hypothese die suggereert dat ovariële metastasen vaker ontstaan in premenopauzale patiënten. ${ }^{45-49}$ Binnen patiënten met ovariële metastasen onderging 27\% CRS-HIPEC, 38\% resectie van de primaire colorectale tumor (met of zonder metastasectomie), $25 \%$ onderging palliatieve therapie, en $9 \%$ onderging geen actieve behandeling. Algehele overleving was het best in patiënten welke CRS-HIPEC ondergingen (mediaan 34 maanden), gevolgd door primaire tumorresectie (mediaan 18 maanden) en palliatieve behandeling (13 maanden). Ondanks de significant betere overleving in patiënten welke CRSHIPEC ondergingen, speelt hierbij een zekere selectie bias. Patiënten welke behalve ovariële metastasen ook (andere) afstandsmetastasen hebben, evenals patiënten met uitgebreide intraperitoneale ziekte ( $\mathrm{PCl}>20)$, zijn doorgaans niet geschikt voor CRS-HIPEC, en hebben meestal een slechtere prognose. ${ }^{21,50,51}$ Aangezien ovariële metastasen vaak gepaard gaan met peritoneale metastasen, en data omtrent de $\mathrm{PCl}$ niet beschikbaar waren in binnen deze studie, blijft het onduidelijk in hoeverre dit effect heeft gehad op survival. Desalniettemin versterkt de significant betere algehele overleving in patiënten welke CRS-HIPEC ondergingen de hypothese dat ovariële metastasen ontstaan als gevolg van peritoneale tumorverspreiding. Op basis van deze studie kan CRS-HIPEC als voorkeursbehandeling geadviseerd worden in geselecteerde patiënten met colorectale ovariële metastasen. 


\section{References}

1. World Health Organisation Global Cancer Observatory.

2. Netherlands Cancer Registry.

3. van der Geest LGM, Lam-Boer J, Koopman M, Verhoef C, Elferink MAG, de Wilt JHW. Nationwide trends in incidence, treatment and survival of colorectal cancer patients with synchronous metastases. Clin Exp Metastasis. 2015. doi:10.1007/s10585-015-9719-0

4. van Gestel YRBM, de Hingh IHJT, van Herk-Sukel MPP, et al. Patterns of metachronous metastases after curative treatment of colorectal cancer. Cancer Epidemiol. 2014. doi:10.1016/j.canep.2014.04.004

5. Lemmens VE, Klaver YL, Verwaal VJ, Rutten HJ, Coebergh JWW, De Hingh IH. Predictors and survival of synchronous peritoneal carcinomatosis of colorectal origin: A populationbased study. Int J Cancer. 2011;128(11):2717-2725. doi:10.1002/ijc.25596

6. Nordlinger B, Sorbye H, Glimelius B, et al. Perioperative chemotherapy with FOLFOX4 and surgery versus surgery alone for resectable liver metastases from colorectal cancer (EORTC Intergroup trial 40983): a randomised controlled trial. Lancet. 2008. doi:10.1016/ S0140-6736(08)60455-9

7. Nordlinger B, Sorbye H, Glimelius B, et al. Perioperative FOLFOX4 chemotherapy and surgery versus surgery alone for resectable liver metastases from colorectal cancer (EORTC 40983): Long-term results of a randomised, controlled, phase 3 trial. Lancet Oncol. 2013. doi:10.1016/S1470-2045(13)70447-9

8. Rovers KP, Simkens GA, Punt CJ, van Dieren S, Tanis PJ, de Hingh IH. Perioperative systemic therapy for resectable colorectal peritoneal metastases: Sufficient evidence for its widespread use? A critical systematic review. Crit Rev Oncol Hematol. 2017. doi:10.1016/j.critrevonc.2017.03.028

9. Bushati M, Rovers KP, Sommariva A, et al. The current practice of cytoreductive surgery and HIPEC for colorectal peritoneal metastases: Results of a worldwide web-based survey of the Peritoneal Surface Oncology Group International (PSOGI). Eur J Surg Oncol. 2018. doi:10.1016/j.ejso.2018.07.003

10. Dohan $A$, Hoeffel $C$, Soyer $P$, et al. Evaluation of the peritoneal carcinomatosis index with CT and MRI. BrJ Surg. 2017. doi:10.1002/bjs.10527

11. Marin D, Catalano C, Baski M, et al. 64-Section multi-detector row CT in the preoperative diagnosis of peritoneal carcinomatosis: Correlation with histopathological findings. Abdom Imaging. 2010. doi:10.1007/s00261-008-9464-9

12. Razenberg LGEM, Lemmens VEPP, Verwaal VJ, et al. Challenging the dogma of colorectal peritoneal metastases as an untreatable condition: Results of a population-based study. Eur J Cancer. 2016;65:113-120. doi:10.1016/j.ejca.2016.07.002

13. Klaver CEL, Groenen H, Morton DG, Laurberg S, Bemelman WA, Tanis PJ. Recommendations and consensus on the treatment of peritoneal metastases of colorectal origin: a systematic review of national and international guidelines. Color Dis. 2017;19(3):224-236. doi:10.1111/codi.13593

14. Simkens GA, van Oudheusden TR, Luyer MD, et al. Serious Postoperative Complications Affect Early Recurrence After Cytoreductive Surgery and HIPEC for Colorectal Peritoneal Carcinomatosis. Ann Surg Oncol. 2015. doi:10.1245/s10434-014-4297-y 
15. Feferman Y, Solomon D, Bhagwandin S, et al. Sites of Recurrence After Complete Cytoreduction and Hyperthermic Intraperitoneal Chemotherapy for Patients with Peritoneal Carcinomatosis from Colorectal and Appendiceal Adenocarcinoma: A Tertiary Center Experience. Ann Surg Oncol. 2019. doi:10.1245/s10434-018-6860-4

16. Leimkühler M, Hemmer PHJ, Reyners AKL, et al. Neoadjuvant chemotherapy followed by cytoreductive surgery and hyperthermic intraperitoneal chemotherapy for colorectal cancer: A feasibility and safety study. World J Surg Oncol. 2019. doi:10.1186/s12957-0181554-8

17. Glockzin G, Zeman F, Croner RS, et al. Perioperative Systemic Chemotherapy, Cytoreductive Surgery, and Hyperthermic Intraperitoneal Chemotherapy in Patients With Colorectal Peritoneal Metastasis: Results of the Prospective Multicenter Phase 2 COMBATAC Trial. Clin Colorectal Cancer. 2018. doi:10.1016/j.clcc.2018.07.011

18. Hurwitz HI, Tebbutt NC, Kabbinavar F, et al. Efficacy and Safety of Bevacizumab in Metastatic Colorectal Cancer: Pooled Analysis From Seven Randomized Controlled Trials. Oncologist. 2013. doi:10.1634/theoncologist.2013-0107

19. Landelijke Werkgroep Gastro Intestinale Tumoren 2019. Richtlijn colorectaal carcinoom Versie 3.0. 2017.

20. Culliford IV AT, Brooks AD, Sharma S, et al. Surgical debulking and intraperitoneal chemotherapy for established peritoneal metastases from colon and appendix cancer. Ann Surg Oncol. 2001. doi:10.1245/aso.2001.8.10.787

21. Glehen O, Kwiatkowski F, Sugarbaker PH, et al. Cytoreductive Surgery Combined with Perioperative Intraperitoneal Chemotherapy for the Management of Peritoneal Carcinomatosis from Colorectal Cancer: A Multi-Institutional Study. J Clin Oncol. 2004. doi:10.1200/JCO.2004.10.012

22. Gilly FN. Phase II studies: International registry of colorectal carcinomatosis. Eur J Surg Oncol. 2006. doi:10.1016/j.ejso.2006.03.030

23. Elias. Peritoneal colorectal carcinomatosis treated with surgery and perioperative intraperitoneal chemotherapy: Retrospective analysis of 523 patients from a multicentric French study (Journal of Clinical Oncology (2010) 28 (63-68)). J Clin Oncol. 2010. doi:10.1200/JCO.2010.29.0163

24. Passot G, Vaudoyer D, Cotte $E$, et al. Progression following neoadjuvant systemic chemotherapy may not be a contraindication to a curative approach for colorectal carcinomatosis. Ann Surg. 2012. doi:10.1097/SLA.0b013e318255486a

25. Cashin PH, Graf W, Nygren P, Mahteme H. Cytoreductive surgery and intraperitoneal chemotherapy for colorectal peritoneal carcinomatosis: Prognosis and treatment of recurrences in a cohort study. Eur J Surg Oncol. 2012. doi:10.1016/j.ejso.2012.03.001

26. Nikolic S, Dzodic R, Zegarac M, et al. Survival prognostic factors in patients with colorectal peritoneal carcinomatosis treated with cytoreductive surgery and intraoperative hyperthermic intraperitoneal chemotherapy: A single institution exprerience. J BUON. 2014. doi:10.1016/j.ejso.2016.06.202

27. Ceelen W, Van Nieuwenhove Y, Putte D Vande, Pattyn P. Neoadjuvant chemotherapy with bevacizumab may improve outcome after cytoreduction and hyperthermic intraperitoneal chemoperfusion (HIPEC) for colorectal carcinomatosis. Ann Surg Oncol. 2014. doi:10.1245/s10434-014-3713-7 
28. Glehen O, Gilly FN, Arvieux C, et al. Peritoneal carcinomatosis from gastric cancer: A multi-institutional study of 159 patients treated by cytoreductive surgery combined with perioperative intraperitoneal chemotherapy. Ann Surg Oncol. 2010. doi:10.1245/ s10434-010-1039-7

29. Maggiori L, Goéré D, Viana B, et al. Should patients with peritoneal carcinomatosis of colorectal origin with synchronous liver metastases be treated with a curative intent?: A case-control study. Ann Surg. 2013. doi:10.1097/SLA.0b013e3182778089

30. Ung L, C. Chua T, L. Morris D. Peritoneal metastases of lower gastrointestinal tract origin: A comparative study of patient outcomes following cytoreduction and intraperitoneal chemotherapy.J Cancer Res Clin Oncol. 2013. doi:10.1007/s00432-013-1517-y

31. Maillet M, Glehen O, Lambert J, et al. Early Postoperative Chemotherapy After Complete Cytoreduction and Hyperthermic Intraperitoneal Chemotherapy for Isolated Peritoneal Carcinomatosis of Colon Cancer: A Multicenter Study. Ann Surg Oncol. 2016. doi:10.1245/ s10434-015-4914-4

32. Quenet F, Elias D, Roca $L$, et al. A UNICANCER phase III trial of hyperthermic intraperitoneal chemotherapy (HIPEC) for colorectal peritoneal carcinomatosis (PC): PRODIGE 7.J Clin Oncol. 2018. doi:10.1200/jco.2018.36.18_suppl.Iba3503

33. Baratti D, Kusamura S, Pietrantonio F, Guaglio M, Niger M, Deraco M. Progress in treatments for colorectal cancer peritoneal metastases during the years 20102015. A systematic review. Crit Rev Oncol Hematol. 2016;100:209-222. doi:10.1016/j. critrevonc.2016.01.017

34. Go??r?? D, Malka D, Tzanis D, et al. Is there a possibility of a cure in patients with colorectal peritoneal carcinomatosis amenable to complete cytoreductive surgery and intraperitoneal chemotherapy? Ann Surg. 2013;257(6):1065-1071. doi:10.1097/ SLA.0b013e31827e9289

35. Van Gestel YRBM, Thomassen I, Lemmens VEPP, et al. Metachronous peritoneal carcinomatosis after curative treatment of colorectal cancer. Eur J Surg Oncol. 2014. doi:10.1016/j.ejso.2013.10.001

36. Segelman J, Granath F, Holm T, MacHado M, Mahteme H, Martling A. Incidence, prevalence and risk factors for peritoneal carcinomatosis from colorectal cancer. $\mathrm{Br} \mathrm{J}$ Surg. 2012. doi:10.1002/bjs.8679

37. Pelz JOW, Stojadinovic A, Nissan A, Hohenberger W, Esquivel J. Evaluation of a peritoneal surface disease severity score in patients with colon cancer with peritoneal carcinomatosis. J Surg Oncol. 2009. doi:10.1002/jso.21169

38. Rovers KP, Simkens GA, Vissers PA, et al. Survival of patients with colorectal peritoneal metastases is affected by treatment disparities among hospitals of diagnosis: A nationwide population-based study. Eur J Cancer. 2017. doi:10.1016/j.ejca.2016.12.034

39. Hentzen JEKR, Rovers KP, Kuipers H, et al. Impact of Synchronous Versus Metachronous Onset of Colorectal Peritoneal Metastases on Survival Outcomes After Cytoreductive Surgery (CRS) with Hyperthermic Intraperitoneal Chemotherapy (HIPEC): A Multicenter, Retrospective, Observational Study. Ann Surg Oncol. 2019. doi:10.1245/s10434-01907294-y

40. Wong JSM, Tan GHC, Chia CS, Ong J, Ng WY, Teo MCC. The importance of synchronicity in the management of colorectal peritoneal metastases with cytoreductive surgery and hyperthermic intraperitoneal chemotherapy. World J Surg Oncol. 2020. doi:10.1186/ s12957-020-1784-4 
41. Yamanishi $Y$, Koshiyama M, Ohnaka M, et al. Pathways of Metastases from Primary Organs to the Ovaries. Obstet Gynecol Int. 2011. doi:10.1155/2011/612817

42. Chang TC, Changchien CC, Tseng CW, et al. Retrograde lymphatic spread: A likely route for metastatic ovarian cancers of gastrointestinal origin. Gynecol Oncol. 1997. doi:10.1006/gyno.1997.4793

43. Antoniades K, Spector HB, Hecksher RH. Prophylactic oophorectomy in conjunction with large-bowel resection for cancer: Report of two cases. Dis Colon Rectum. 1977. doi:10.1007/BF02586590

44. Ojo J, De Silva S, Han E, Lin P, Wakabayashi M, Lai L. Krukenberg tumors from colorectal cancer: presentation, treatment and outcomes. Am Surg. 2011;77.10:1381-1385.

45. O'brien PH, Newton BB, Metcalf JS, Rittenbury M. Oophorectomy in women with carcinoma of the colon and rectum. Surg Gynecol Obstet. 1981;153(6):827-830.

46. Kim DD, Park IJ, Kim HC, Yu CS, Kim JC. Ovarian metastases from colorectal cancer: A clinicopathological analysis of 103 patients. Color Dis. 2009;11(1):32-38. doi:10.1111/ j.1463-1318.2008.01543.x

47. Kim WY, Kim TJ, Kim SE, et al. The role of cytoreductive surgery for non-genital tract metastatic tumors to the ovaries. Eur J Obstet Gynecol Reprod Biol. 2010;149(1):97-101. doi:10.1016/j.ejogrb.2009.11.011

48. Ayhan A, Sel Tuncer ZÇ, Bükülmez O. Malignant tumors metastatic to the ovaries. J Surg Oncol. 1995. doi:10.1002/jso.2930600411

49. Miller BE, Pittman B, Wan JY, Fleming M. Colon cancer with metastasis to the ovary at time of initial diagnosis. Gynecol Oncol. 1997. doi:10.1006/gyno.1997.4811

50. Simkens GA, Rovers KP, Nienhuijs SW, de Hingh IH. Patient selection for cytoreductive surgery and HIPEC for the treatment of peritoneal metastases from colorectal cancer. Cancer Manag Res. 2017. doi:10.2147/CMAR.S119569

51. 51. da Silva RG, Sugarbaker PH. Analysis of Prognostic Factors in Seventy Patients Having a Complete Cytoreduction plus Perioperative Intraperitoneal Chemotherapy for Carcinomatosis from Colorectal Cancer. J Am Coll Surg. 2006. doi:10.1016/j. jamcollsurg.2006.08.024 